\title{
The Impact of National Culture on Worldwide eGovernment Readiness
}

\author{
Zlatko J Kovačić \\ The Open Polytechnic of New Zealand, Wellington, New Zealand
}

Zlatko.Kovacic@openpolytechnic.ac.nz

\begin{abstract}
Diffusion of information and communication technologies is a global phenomenon. In spite of rapid globalization there are considerable differences between nations in terms of the adoption and usage of new technologies. Several studies exploring causal factors including national cultures of information and communication technology adoption have been carried out. The focus of this paper is slightly different from other studies in this area. Rather than concentrating on the individual information technology an overall eGovernment readiness is the focus. This research conducted an analysis of the impact national culture has on eGovernment readiness and its components for 95 countries. eGovernment readiness assessment used in this study is based on the UN Global eGovernment Survey 2003, while the national cultural dimensions were identified using Hofstede's model of cultural differences. The research model and hypotheses were formed and tested using correlation and regression analysis. The findings indicate that worldwide eGovernment readiness and its components are related to culture. The result has theoretical and practical implications.
\end{abstract}

Keywords: National Culture, eGovernment Readiness, Cross-Cultural Studies, Information Technology Adoption, Diffusion of the Internet, Hofstede

\section{Introduction}

In the last decade we have witnessed a rapid rate of Internet penetration worldwide. Although this Internet diffusion happened on a global scale there are significant differences between countries in terms of how far they went and how fast they have adopted new information and communication technology (hereafter labeled ICT) as was shown by Maitland \& Bauer (2001). Since the adoption of a new technology varies between countries it is important to construct a composite measure of the country's overall readiness to adopt and use a new technology and also to measure factors that contribute to the adoption of ICT. Various factors influencing Internet adoption have been considered in several studies. It was confirmed that telecommunication infrastructure (Hargittai, 1999), socio-economic factors (Robinson \& Crenshaw, 1999) and cultural values (Maitland

Material published as part of this journal, either online or in print, is copyrighted by the publisher of Informing Science. Permission to make digital or paper copy of part or all of these works for personal or classroom use is granted without fee provided that the copies are not made or distributed for profit or commercial advantage AND that copies 1) bear this notice in full and 2) give the full citation on the first page. It is permissible to abstract these works so long as credit is given. To copy in all other cases or to republish or to post on a server or to redistribute to lists requires specific permission and payment of a fee. Contact Editor@inform.nu to request redistribution permission.
\& Bauer, 2001) have a significant influence on ICT adoption among countries.

A country's overall readiness to adopt, use and benefit from using ICT is called country's eReadiness. A knowledge of the factors which make a significant contribution to eReadiness and the country's position on the eReadiness scale would help the country's leaders to identify the strengths 
and weaknesses of the country's current position and to concentrate on the areas where improvement and further integration of ICT could be made (Bridges.org, 2001). An important component of the country's overall eReadiness is its government readiness to operate and benefit from the new environment. The concepts of electronic government (hereafter labeled eGovernment) has not been uniquely defined and used in literature. For example, Turban, King, Lee, Warkentin, \& Chung, (2002, p. 452) listed six different eGovernment definitions. However, we may say that the 'use of Internet technologies', 'access to information', 'service delivery' and 'participation' are the most common keywords used in eGovernment definitions. Simply, eGovernment could be defined as the government's use of ICT to serve both internally and externally through its organizational structures and activities. The label 'eGovernment readiness' is used to describe government readiness to adopt, use and benefit from ICT, and it also forms one of the main focuses of analysis. The concept of eGovernment readiness is important because of the opportunities it creates for each country in terms of benefiting from eCommerce activities, openness to globalization, potential to strengthen democracy and make governments more responsive to the needs of their citizens, increasing citizen wellbeing, etc.

The second focus in analysis is on the role that culture has in the adoption of ICT. Cultural differences between countries in general and particularly in relation to information technology adoption is a highly researched subject. The concept of culture adopted and used in this paper is based on works of Dutch anthropologist Geert Hofstede who defines culture as "a system of collectively held values". The following authors identified cultural values as one of influential factors on adoption of ICT: Bagchi, Cerveny, Hart \& Peterson (2003), Johns, Smith \& Strand (2003), Maitland \& Bauer (2001) and Sørnes, Stephens, Sætre, \& Browning (2004). Others also recognize the role culture could have in adopting ICT; for example, Bridges.org (2001) suggests that: “... unique cultural and historical environment of a region must be taken into account as part of a national ICT policy to truly gauge the country's eReadiness for the future." In other words, each country should find its own way to the optimal eGovernment readiness which is consistent with the national culture.

The main objective of this research is to investigate the relationship between national culture and eGovernment readiness. More specifically the purpose of this research is to provide a theoretical framework for the impact of national culture on eGovernment readiness and to test whether the national cultural dimensions have significant impact on the eGovernment readiness. While most of other papers in this area are focused on an individual indicator of a country's eReadiness (for example, the number of Internet hosts or the number of PCs per 100 citizens) this paper is the first to use a synthetic indicator to measure eGovernment readiness. In addition, the data set for this paper includes the largest number of countries in comparison to data sets in other papers.

In the next two sections we review eGovernment readiness frameworks and the relationship between national culture and ICTs, providing the theoretical foundation for our empirical analysis. Based on deduction from theory and previous empirical work the third section will provide the answer to the question, how does culture influence eGovernment readiness? The following two sections report data, method of analysis, results and a discussion of the results. In the final section some implications of this research will be presented.

\section{eGovernment Readiness Frameworks}

In this paper, eGovernment readiness is defined as the aptitude of a government to use ICTs to move its services and activities into the new environment (a similar definition was given in UN, 2003, p. 11). The reason why eGovernment readiness is important to monitor and assess is explained in Bridges.org (2001), for country's eReadiness: "It is increasingly clear that for a country to put ICT to effective use, it must be 'eReady' in terms of infrastructure, the accessibility of ICT to the population at large, and the effect of the legal and regulatory framework on ICT use. If the 
digital divide is going to be narrowed, all of these issues must be addressed in a coherent, achievable strategy that is tailored to meet the local needs of particular countries."

The most complete assessment of eGovernment readiness including 190 countries was undertaken by the United Nations in 2001 and 2003. The United Nations Division for Public Economics and Public Administration, together with the American Society for Public Administration, started a project in 2001 analyzing the eGovernment environment of 190 UN Member States. The conceptual frame they used postulates that the state of eGovernment readiness is a function of the combined level of a country's state of readiness, economic, technological development and human resource development. A final product of their analysis was the construction of a synthetic indicator named the eGovernment Index. Two years later in 2003, the UN Department of Economic and Social Affairs and the Civic Resource Group presented a second survey slightly changing the definition of the eGovernment index and naming it the eGovernment Readiness Index. Three important indices contribute to this index: the web measure index, the telecommunication infrastructure index and the human capital index as described in Table 2. An alternative measure of eGovernment readiness was provided in the World Markets Research Centre Survey (West, 2001). It focuses on the features national government web sites are offering. It may be said that this index tries to capture the same phenomenon as the UN web measure index.

The adoption of an eGovernment initiative or UN framework for assessment of an eGovernment readiness is basically a supply-side approach to eGovernment analysis using data about the national government web sites, telecommunication infrastructure and human capital rather than a demand-side approach, which is based on the real use of the eGovernment web sites by the citizens, businesses and government or their perceptions about quality of the online services delivery. In this paper measurement and assessment of eGovernment readiness was based on the United Nations (2003) framework. There are two reasons for adopting the UN eGovernment readiness framework in this paper: the framework includes more countries than any other study and the data is gathered in a consistent manner covering key areas of any eReadiness assessment study, i.e. technological infrastructure and human capital component. Unfortunately this framework does not provide data to apply a demand-side approach while the other studies which took both, a supply and demand-side approach (Altman, 2002; Graafland-Essers \& Ettedgui, 2003) are limited to Latin American and European data only.

There were also other assessments of eGovernment readiness worldwide (West, 2001) or at the different levels of federal, state or local governments (Holden, Norris \& Fletcher, 2003; West, 2000) or regions of the world (Altman, 2002). West (2000) assessed federal and state eGovernments in US. He found that "the eGovernment revolution has fallen short of its potential. Government websites are not making full use of available technology, and there are problems in terms of access and democratic outreach". Altman (2002) assessed eGovernment in Latin America. Surprisingly he didn't find a direct proportional relation between those countries with high potentiality (readiness) and those with actual broad use of eGovernment. His research is of particular interest because it brings together the supply-side and demand-side approaches to eGovernment analysis. Graafland-Essers \& Ettedgui (2003) assessed eGovernments in Europe also taking both supply-side and demand-side approaches. Bridges.org (2001) provides a very detailed list and comparison of eReadiness assessment models which were developed until 2001.

Choucri, Maugis, Madnick, \& Siegel (2003) critically considered these, what they called 'first generation' eReadiness models and setup a theoretical framework for the 'next generation' of eReadiness models. Defining eReadiness "as the ability to pursue value creation opportunities facilitated by the use of the Internet" (p. 4), they derived a key element of their framework from the answer to the question: eReadiness for what? According to them, an eReadiness indicator should measure the degree of ability and the capacity to pursue, but emphasis in the framework should be put on value creation opportunities. Another framework of national eReadiness was 
given in Bui, Sankaran \& Sebastian (2003). Their framework is based on eight factors: digital infrastructure, macro economy, ability to invest, knowledgeable citizens, competitiveness, access to a skilled workforce, culture, and the cost of living and pricing. A total of 52 indicators were used to quantify these 8 factors. A detailed analysis of each individual country's eReadiness with all components included would probably require the use of the 'next generation' of eReadiness models, to make a decision about the optimal approach to implementation of ICT. However, to identify the impact various factors could have on the global eGovernment readiness, derivation of a synthetic indicator is sufficient. The main reason for not using one of proposed 'next generation' of eReadiness models is a lack of the full set of data for most of the countries. Usually complete and reliable data is available only for developed countries.

Research studies which considered the various factors having an impact on the ICT adoption confirmed that telecommunication infrastructure (Hargittai, 1999), socio-economic factors (Robinson \& Crenshaw, 1999) and cultural values (Maitland \& Bauer, 2001) contributed to the explanation of differences in Internet diffusion between countries. We would also expect that in a democratic political system the government will foster the design and development of various channels for providing their services to the citizens. Indeed, research has examined the impact of democracy, corruption and globalization on eGovernment readiness and found that more democratic countries are higher ranked on the eGovernment readiness list than the less democratic countries (Kovačić, 2005). He found significant positive correlations between eGovernment readiness and democracy (Freedom House index) and between eGovernment readiness and globalization. Of course the degree of eGovernment service adoption does not depend only on the level of democracy in the country but also on the cost of implementation, the perceived political benefits for the government from implementing an eGovernment initiative and other factors. As Bretschneider, Gant \& Ahn (2003) suggested, the degree of eGovernment service adoption could be explained in terms of the perceived administrative benefit from adopting eGovernment services, the political nature of online applications, the government's organizational capacity in adopting new information technology, and the diffusion effect of eGovernment service technology.

\section{National Culture and ICTs}

The concept of culture is not uniquely defined in literature. As Sørnes, Stephens, Sætre \& Browning (2004) pointed out over 400 definitions of culture have been identified. Fortunately, in most of these definitions a commonly held view is that the cultural environment influences and shapes the values shared by the members of the society. Hofstede (1981), whose four-dimensional cultural model was used in this paper, wrote that "... culture is the collective programming of the human mind that distinguishes the members of one human group from those of another. Culture in this sense, is a system of collectively held values" (p. 24). He emphasized that "in the center is a system of societal norms, consisting of the value systems (the mental programs) shared by most of the population" (p.24). According to him, culture is an "interactive aggregate of common characteristics", "a collective phenomenon" which "is learned, not inherited" (p. 24).

Though the Hofstede model of culture is the most well-known classification of culture it is not the only one used in literature. Chanchani \& Theivanathampillai (2002) investigate and discusse alternative classification of culture to Hofstede's classification based on the works of Triandis, Trompenaars and Fiske. They have set up a framework for comparing alternative classifications, evaluating the sufficiency and adequacy of these classifications. One of their suggestions is to use a classification of culture based upon the research objective. The Hofstede model is recommended in the following case "... if the researcher wishes to use an instrument or has collated data then correlation with Hofstede's data may be considered" (p. 15). McSweeney (2002) also criticized Hofstede's model of national cultural differences. He focused his critique on the Hofstede research methodology arguing that the quality of evidence in the Hofstede model of na- 
tional culture is poor and the set of assumptions are not justified. However, in spite of criticisms the Hofstede model of culture has been widely used in the literature in the last two decades. There have been also numerous studies on the relationship between national culture and the use and adoption of ICTs. The following authors: Bagchi, Cerveny, Hart \& Peterson (2003), Johns, Smith \& Strand (2003), Maitland \& Bauer (2001), Robinson \& Crenshaw (1999) and Veiga, Floyd \& Dechant (2001) concluded that the significant variation in Internet diffusion, IT implementation and acceptance between countries could be attributed to national culture as described by Hofstede's cultural model. Sørnes, Stephens, Sætre \& Browning (2004) provided an excellent overview of the literature and a list of relevant studies on how ICTs impact culture and how culture impacts on ICT practices.

Based on 116,000 questionnaires Hofstede $(1980,1983)$ collected data from 50 countries and 3 regions about the work-related value patterns of employees in IBM, a large multinational firm. By using data from one firm only Hofstede controlled for a number of industry and company variables so that he could focus on cultural differences. Using correlation and factor analysis he revealed four largely independent dimensions of differences between national value systems: (1) power distance (large vs. small), (2) individualism vs. collectivism, (3) masculinity vs. femininity, and (4) uncertainty avoidance (strong vs. weak). Later Hofstede identified a fifth dimension, dealing with long versus short-term orientation, replying to those who criticized his cultural model to be biased toward Western culture.

The Power Distance dimension reflects the perception that members of society have about unequal distribution of power in institutions and organizations and the extent to which it is accepted in a society. People in countries where power distance is large accept a hierarchical order in which everybody has a place that needs no further justification. Countries with small power distance allow upward social mobility of its citizens and their participation in the process of decision making. One of the conditions for such citizen's participation would be the implementation of various communication technologies which would support and help this participation happen. Therefore it could be argued that a country with a larger power distance would have a negative attitude toward implementing and using ICTs.

The Individualism/Collectivism dimension describes the relationship between individuals and the group in a society. For the countries with low individualism, i.e. high collectivism, people consider the group as the main source of their identity. On the other hand, an individualistic culture would pay more attention to the performance of the individual. Time management would be important and any technology that could help individuals to perform more efficiently would be highly regarded and quickly accepted. Therefore it could be argued that the country with a strong individualistic culture would have a positive attitude toward implementing and using ICTs.

The Masculinity/Femininity dimension describes the achievement orientation in a society. When the preferences in society are for achievement, assertiveness, and material success then the country is ranked high on masculinity. On the other side, cultures that rank low on masculinity, i.e. high on femininity, prefer relationships, caring for the weak, and the quality of life. A high masculinity index indicates a culture that emphasizes masculine values and has very separate and rigid gender roles and expectations. Some authors, such as Bagchi, Cerveny, Hart \& Peterson (2003) argued that "ITs promote more cooperation at work, better quality of life and these values are espoused in nations with low MF index" (p. 960). However, it could be argued equally well that in a country with high masculinity there would also be a positive attitude toward implementing ICTs if these technologies improve performance, increase the chance of success and support competition, which are all key factors of a masculine culture. In other words the masculinity/femininity dimension could have at least at the conceptual level a mixed impact on the ICTs. 
The Uncertainty Avoidance dimension describes the degree to which members of a society feel uncomfortable with uncertainty and ambiguity, preferring structured over unstructured situations. Members of societies with strong uncertainty avoidance would tend to avoid or reduce the risk induced by the unknown, i.e. unstructured situation, while people from countries with weak uncertainty avoidance could be described as 'risk takers'. It could be expected that countries with strong uncertainty avoidance would be slow in the adoption and use of new ICTs, while the countries on the opposite end of this scale would be leaders in implementing new ICTs and willing to take the risk of failure. Therefore it could be argued that the country with a strong uncertainty avoidance culture would have a negative attitude toward implementing and using ICTs.

All four dimensions of the Hofstede cultural model were included in the later empirical analysis. As statisticians say 'let the data speak for itself'. However, in the literature not all four dimensions were considered to be relevant for research on the impact of national culture on the ICTs adoption. For example in Maitland \& Bauer (2001) only uncertainty avoidance dimension from

Table 1: Countries with highest and lowest cultural dimensions values

\begin{tabular}{|l|l|l|l|l|l|l|l|}
\hline \multicolumn{2}{|c|}{ Power Distance } & \multicolumn{2}{c|}{ Individualism } & \multicolumn{2}{c|}{ Masculinity } & \multicolumn{2}{c|}{ Uncertainty Avoidance } \\
\hline \multicolumn{1}{|c|}{ Max } & \multicolumn{1}{|c|}{ Min } & \multicolumn{1}{c|}{ Max } & Min & \multicolumn{1}{c|}{ Max } & \multicolumn{1}{c|}{ Min } & \multicolumn{1}{c|}{ Max } & Min \\
\hline Slovakia 107 & Austria 11 & US 91 & Guatemala 6 & Slovakia 110 & Sweden 5 & Greece 112 & Singapore 8 \\
\hline Malaysia 104 & Israel 13 & Australia 90 & Ecuador 8 & Japan 95 & Norway 8 & Portugal 104 & Jamaica 13 \\
\hline Iraq 95 & Denmark 18 & UK 89 & Panama 11 & Hungary 88 & Iceland 10 & Guatemala 101 & Denmark 23 \\
\hline
\end{tabular}

Source: Hofstede (2004)

the Hofstede model has been included. However, they have added two other variables which might be considered as cultural variables: gender equality and English language. Also, Johns, Smith \& Strand (2003) included the individualism/collectivism and uncertainty avoidance dimensions only. They felt that achievement orientation (masculinity/femininity dimension) has a mixed impact on the use of technology. The same conclusion was drawn for power distance dimension and its impact on the use of technology.

To illustrate the four Hofstede cultural dimension values, three countries were selected from the list of all countries, those with extreme values (maximum and minimum) on each dimension and their scores were presented in Table 1. For example, Slovakia scores 110 on masculinity and Sweden 5 reflecting the fact that Slovakia is a 'masculine' society where men are tough and concerned with material success, whereas women are more tender and interested in quality of life. On the other side of the masculinity/femininity scale Sweden is a 'feminine' society where both men and women are equally concerned with quality of life.

\section{How does Culture Influence eGovernment Readiness?}

Figure 1 describes the model of influence that national culture has on eGovernment readiness. The arrow in the cultural environment block illustrates the assumption that national culture affects society's basic values. People of the country are using these basic values as a foundation to build and shape the whole legal environment and a legal system with its three constitutive components: legislature, executive and judiciary. Then the legal environment and the legal system influences whether and how the government will use the new ICTs to support its internal and external activities. External to this model are socio-economic, technological and other factors which may influence eGovernment readiness.

Though in his conceptualization Hofstede treated national culture as systematically causal, we can argue along the same line with Sørnes, Stephens, Sætre \& Browning (2004) that "the relationship between organizational cultures and ICTs is not simply causal. Either one can cause changes in the other, because technology is part of culture and vice versa." In other words, there 


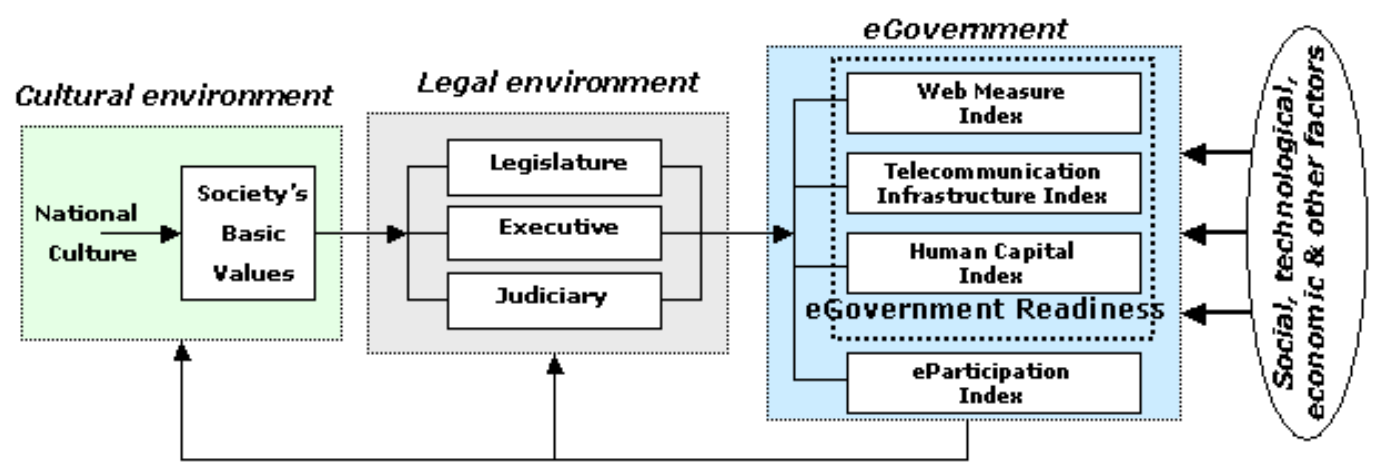

Figure 1: Model of the impact of national culture on the eGovernment readiness

is a reflexive and dynamic relationship between national culture and ICTs rather than causal. Therefore, arrows, i.e. feedback links from eGovernment block to legal and cultural environment blocks in Figure 1 have been added to take into account the impact that eGovernment may have on the national culture and legal system. However these feedback links were not analyzed further for the methodological reasons explained later.

Based on the model in Figure 1, the above discussion of Hofstede's four cultural dimensions and the attitude that the country and its government might have toward using ICTs the following research hypotheses are offered:

Hypothesis H1: The government of a country with a larger power distance would have a negative attitude toward increasing the level of eGovernment readiness

Hypothesis H2: The government of a country with a strong individualistic culture would have a positive attitude toward increasing the level of eGovernment readiness

Hypothesis H3: The government of a country with a high/low masculine culture would have a positive attitude toward increasing the level of eGovernment readiness

Hypothesis H4: The government of a country with a strong uncertainty avoidance culture would have a negative attitude toward increasing the level of eGovernment readiness

\section{Data and Methodology}

Data for this paper was collected from three different sources and was available for 95 countries. While the data for eGovernment readiness and GDP per capita were available for 190 countries, the major constraint came from a database containing cultural dimensions scores (Hofstede, 2004), i.e. data for only 95 countries was available. Generally, one of the main difficulties in assessing worldwide eReadiness including eGovernment readiness and the effect that national culture might have on ICTs adoption and their use, is a lack of data which would cover most of the countries around the world and would be available for all indicators to be included in analysis. Table 2 describes the definition of variables in detail, their acronyms and data sources used.

The reason for including GDP per capita in an analysis is explained by Hofstede (1980). He suggested including economic variables such as GDP per capita when examining the effect of national culture. When the effect of others hard variables (economic variables, for example) are significant, then the cultural variables are redundant. If the cultural variables are still significant in spite of included economic variables, then the effect of culture on observed phenomenon, i.e. eGovernment readiness and its components could be confirmed. 
Methods of correlation and regression analysis were applied to the data. For statistical reasons explained in the following section, three alternative methods of estimation were used to estimate eGovernment readiness regression models: ordinary least squares (hereafter labeled OLS), ordinary least squares with correction for heteroskedasticity (hereafter labeled OLS (H. C.)) and seemingly unrelated regressions (hereafter labeled SUR). Also, to address the problem of possible multicollinearity (high correlation within the subset of explanatory variables, which includes cultural variables and GDP per capita) a method of ridge regression was used.

For calculations in this paper we used the EasyReg software package written by Bierens (2004) and SPSS for Windows version 11.5.

Table 2: Description of variables, acronyms and data sources

\begin{tabular}{|c|c|}
\hline Acronym & Description \\
\hline eGOV & $\begin{array}{l}\text { eGovernment Readiness Index is a composite index based on the Web Measure Index, } \\
\text { the Telecommunication Infrastructure Index and the Human Capital Index. [Source: } \\
\text { United Nations (2003)] }\end{array}$ \\
\hline WMI & $\begin{array}{l}\text { Web Measure Index is a quantitative index which measures the generic aptitude of } \\
\text { governments to employ eGovernment as a tool to inform, interact, transact and net- } \\
\text { work. [Source: United Nations (2003)] }\end{array}$ \\
\hline TII & $\begin{array}{l}\text { Telecommunication Infrastructure Index is a composite, weighted average index of six } \\
\text { primary indices, based on basic infrastructural indicators that define a country's ICT } \\
\text { infrastructure capacity. These six indices are: PCs/1,000 persons; Internet users/1,000 } \\
\text { persons; Telephone lines/1,000; On-line population/1,000 persons; Mobile } \\
\text { phones/1,000 persons; and TVs/1,000 persons. [Source: United Nations (2003)] }\end{array}$ \\
\hline $\mathrm{HCI}$ & $\begin{array}{l}\text { Human Capital Index is based on the United Nations Development Programme "edu- } \\
\text { cation index". This is a composite of the adult literacy rate and the combined primary, } \\
\text { secondary and tertiary gross enrolment ratio, with two thirds of weight given to adult } \\
\text { literacy and one third to the gross enrolment ratio. [Source: United Nations (2003)] }\end{array}$ \\
\hline ePART & $\begin{array}{l}\text { eParticipation Index is a qualitative measure which employs proxy indicators for the } \\
\text { quality, relevance, usefulness and willingness of government websites to provide on- } \\
\text { line information and participatory tools and services to people. [Source: United Na- } \\
\text { tions (2003)] }\end{array}$ \\
\hline PDI & $\begin{array}{l}\text { Power Distance Index is a cultural construct developed by Geert Hofstede and inter- } \\
\text { preted as the degree of equality, or inequality, between people in a country's society. } \\
\text { [Source: Hofstede (2004)] }\end{array}$ \\
\hline IDV & $\begin{array}{l}\text { Individualism is a cultural construct developed by Geert Hofstede and interpreted as } \\
\text { the degree a society reinforces individual or collective achievement and interpersonal } \\
\text { relationships. [Source: Hofstede (2004)] }\end{array}$ \\
\hline MAS & $\begin{array}{l}\text { Masculinity is a cultural construct developed by Geert Hofstede and interpreted as the } \\
\text { degree a society reinforces, or does not reinforce, the traditional masculine work role } \\
\text { model of male achievement, control, and power. [Source: Hofstede (2004)] }\end{array}$ \\
\hline UAI & $\begin{array}{l}\text { Uncertainty Avoidance Index is a cultural construct developed by Geert Hofstede and } \\
\text { interpreted as the extent to which the members of a culture feel threatened by uncertain } \\
\text { or unknown situations, i.e. unstructured situations. [Source: Hofstede (2004)] }\end{array}$ \\
\hline GDP & $\begin{array}{l}\text { Gross Domestic Product per capita in } 2002 \text { - purchasing power parity. [Source: CIA's } \\
\text { World Factbook, CIA (2003)] }\end{array}$ \\
\hline
\end{tabular}




\section{Results}

Is there a relationship between cultural dimensions and eGovernment readiness and its components? Pearson's correlation coefficients were calculated to test the hypotheses that the eGovernment readiness and its components correlate with the Hofstede's national cultural constructs. Results are presented in Table 3. The figure between the brackets shows the $P$-value, i.e. the level of significance. The $P$-value indicates the likelihood of obtaining a correlation coefficient as large as that observed if it occurred simply from randomness in the data. A low $P$-value implies that we would probably not observe such a large correlation coefficient from purely random data and the coefficient must be the result of a linear relationship between observed series.

Three results emerge from the correlation matrix presented in Table 3. Firstly, eGovernment readiness and all its components are highly negatively correlated with Power Distance Index (correlation coefficients are in range from -0.411 to -0.687) and positively with Individualism (correlation coefficients are in range from 0.512 to 0.738 ). High individualism (countries where individual rights are paramount) accompanied with smaller power distance (those countries which allow upward social mobility of its citizens) characterized a society in which eGovernment readiness is at the higher level than in the collectivistic countries with larger power distance. There are no statistically significant correlations between eGovernment readiness and other two cultural dimensions, Masculinity and Uncertainty Avoidance Index. Contrary to other studies where Uncertainty Avoidance Index was argued to be one of the most relevant cultural construct which explain ICTs adoption, in this analysis Uncertainty Avoidance Index was not statistically related to any other variables included, beside two cultural constructs, i.e. Power Distance Index (correlation coefficient 0.177 , significant at $8.4 \%$ level) and Individualism $(-0.198$, significant at $5.3 \%$ level).

Secondly, within a subset of national cultural components there is a highly significant negative correlation between Power Distance Index and Individualism, while all the other correlation coefficients are insignificant at the usual 5\% level. This result, i.e. corr(IDV, PDI) $=-0.625$ confirms Hofstede's proposition that a collectivist country is also likely to be a high power distance country. However, from methodological point this result could cause a multicollinearity problem when it comes to the estimation and interpretation of regression models for eGovernment readiness and will be address later.

Table 3: Pearson's correlation matrix

\begin{tabular}{|c|c|c|c|c|c|c|c|c|c|}
\hline & eGOV & & & & & & & & \\
\hline WMI & $\begin{array}{c}.882^{* *} \\
(0)\end{array}$ & WMI & & & & & & & \\
\hline TII & $\begin{array}{c}.918^{* *} \\
(0)\end{array}$ & $\begin{array}{c}.707^{* *} \\
(0)\end{array}$ & TII & & & & & & \\
\hline HCI & $\begin{array}{c}.830^{* *} \\
(0)\end{array}$ & $\begin{array}{c}.594^{* *} \\
(0)\end{array}$ & $\begin{array}{c}.668^{* *} \\
(0)\end{array}$ & HCI & & & & & \\
\hline ePART & $\begin{array}{c}.802^{* *} \\
(0)\end{array}$ & $\begin{array}{c}.875^{* *} \\
(0)\end{array}$ & $\begin{array}{c}.673^{* * *} \\
(0)\end{array}$ & $\begin{array}{c}.540^{* *} \\
(0)\end{array}$ & $\begin{array}{c}\text { ePAR } \\
\text { T }\end{array}$ & & & & \\
\hline PDI & $\begin{array}{c}-.627^{* *} \\
(0)\end{array}$ & $\begin{array}{c}-.515^{* *} \\
(0)\end{array}$ & $\begin{array}{c}-.687^{* *} \\
(0)\end{array}$ & $\begin{array}{c}-.411^{* *} \\
(0)\end{array}$ & $\begin{array}{c}-.513^{* *} \\
(0)\end{array}$ & PDI & & & \\
\hline IDV & $\begin{array}{c}.706^{* *} \\
(0)\end{array}$ & $\begin{array}{c}.581^{* *} \\
(0)\end{array}$ & $\begin{array}{c}.738^{* *} \\
(0)\end{array}$ & $\begin{array}{c}.512^{* *} \\
(0)\end{array}$ & $\begin{array}{c}.631^{* *} \\
(0)\end{array}$ & $\begin{array}{c}-.625^{* *} \\
(0)\end{array}$ & IDV & & \\
\hline MAS & $\begin{array}{l}-.039 \\
(.708)\end{array}$ & $\begin{array}{l}.020 \\
(.851)\end{array}$ & $\begin{array}{l}-.117 \\
(.257)\end{array}$ & $\begin{array}{l}.015 \\
(.887)\end{array}$ & $\begin{array}{l}.032 \\
(.755)\end{array}$ & $\begin{array}{l}.125 \\
(.226)\end{array}$ & $\begin{array}{l}.058 \\
(.574)\end{array}$ & MAS & \\
\hline UAI & $\begin{array}{l}-.010 \\
(.927)\end{array}$ & $\begin{array}{l}-.064 \\
(.537)\end{array}$ & $\begin{array}{l}-.071 \\
(.494)\end{array}$ & $\begin{array}{l}.153 \\
(.140)\end{array}$ & $\begin{array}{l}-.111 \\
(.284)\end{array}$ & $\begin{array}{l}.177^{*} \\
(.084)\end{array}$ & $\begin{array}{c}-.198^{*} \\
(.053)\end{array}$ & $\begin{array}{l}.033 \\
(.746)\end{array}$ & UAI \\
\hline GDP & $\begin{array}{c}.869^{* *} \\
(0)\end{array}$ & $\begin{array}{c}.667^{* *} \\
(0)\end{array}$ & $\begin{array}{c}.942^{* *} \\
(0)\end{array}$ & $\begin{array}{c}.644^{* *} \\
(0)\end{array}$ & $\begin{array}{l}-.194 \\
(.313)\end{array}$ & $\begin{array}{c}-.655^{* *} \\
(0)\end{array}$ & $\begin{array}{c}.738^{* *} \\
(0)\end{array}$ & $\begin{array}{l}.001 \\
. .996)\end{array}$ & $\begin{array}{l}-.020 \\
(.848) \\
\end{array}$ \\
\hline
\end{tabular}

See Table 2 for description of variables 
Thirdly, the absolute value of the correlation coefficient between GDP per capita and all eGovernment readiness indices (ePART is the only exception) is higher than the correlation coefficients of eGovernment readiness indices with any cultural dimension. This result might suggest that economic factors, as measured by GDP per capita, are more important than any other cultural construct, or even the only one which explain variation in the level of eGovernment readiness. This will be tested using a regression model which includes both GDP and cultural variables.

Furthermore, significant correlation coefficient corr(GDP, IDV) $=0.738$ confirmed another proposition from Hofstede's work. He indicated a strong relationship between a country's national wealth and the degree of individualism in its culture. Richer countries tend to be more individualistic, whereas poorer countries are more collectivist. As a poor country grows richer it tends to move away from a collective pattern to an individualistic one. Also, positive correlation coefficients between GDP and eGovernment readiness indices mean that developed countries are better prepared for implementation of eGovernment initiative.

Finally, a positive correlation between Individualism and eParticipation Index, i.e. corr(ePART, IDV) $=0.631$ is consistent with the results in Kim \& Bonk (2002). They indicated that low and high context communication is a function of individualism and collectivism. Members of individualistic cultures prefer direct, explicit, and unambiguous communication. In contrast, members of collectivistic cultures tend to be indirect, implicit and reserved when communicating with others. Thus, in a general sense, low-context communication is prevalent among members of individualistic cultures, whereas members of collectivistic cultures use predominantly high-context communication.

After the correlation analysis a regression analysis was used to get further insight into the relationship between the variables considered in this paper. However, at this stage it cannot be assumed that the national culture is truly exogenous, in other words, that there is one-way causation between national culture and eGovernment readiness (i.e. national culture $\rightarrow$ eGovernment readiness). The same was pointed out by Slack \& Wise (2002) who argued that there is a reflexive relationship between cultures and ICTs, i.e. the relationship between culture and ICTs is not simple causal. Therefore we could argue equally well that the eGovernment readiness could have an impact on national culture. So, if we have a two-way causation in a function such as eGovernment readiness (i.e. national culture $\leftrightarrow$ eGovernment readiness), this implies that the eGovernment readiness function cannot be treated in isolation as a single equation model, but belongs to a wider system of equations that describe the relationships between the relevant variables. This system of equations, known in econometrics as a simultaneous equation system, would be more appropriate to use for a full description of such complex social phenomena as a national culture, eGovernment and its components. However, at this stage we have estimated a single regression equation for each of the key variables (eGovernment readiness indices and eParticipation) in spite of the fact that the estimation method used (ordinary least squares) will produce a biased estimate of the effects that national culture has on eGovernment readiness. This result is due to a violation of the assumptions of the estimation method used, which creates what is known as simultaneous equations bias.

Table 4: Summary of regression results (models with cultural variables only)

\begin{tabular}{|c|c|c|}
\hline Dependent variable & $\begin{array}{l}\text { Variable with significant } \\
\text { t-test at } 5 \% \text { level ( } \beta \text {-coeff.) }\end{array}$ & $\mathbf{R}^{2}$ \\
\hline Web Measure Index & PDI(-0.26), IDV(+0.43) & 0.38 \\
\hline Telecommunication Infrastructure Index & PDI(-0.35), IDV(+0.54) & 0.65 \\
\hline Human Capital Index & $\operatorname{IDV}(+0.46), \mathrm{UAI}(+0.27)$ & 0.35 \\
\hline eGovernment Readiness Index & $\operatorname{PDI}(-0.31), \operatorname{IDV}(+0.55)$ & 0.58 \\
\hline eParticipation Index & $\operatorname{IDV}(+0.51)$ & 0.42 \\
\hline
\end{tabular}

See Table 2 for description of variables 
Regression analysis was carried out in two steps. In the first step eGovernment readiness indices were regressed on all four cultural indicators. A summary of the OLS regression results is presented in Table 4. The first column lists dependent variables, the second column shows which cultural index is significant at the 5\% level and the value of its standardized $\beta$ coefficient.

Standardized $\beta$ coefficients are used to make statements about the relative importance of the independent variables in a regression model. A higher $\beta$ value means that the particular variable is more important that the others. The coefficient of determination $R^{2}$ measures the proportion of the variation in the dependent variable "explained" by the regression model (last column in Table 4). The results reported in Table 4 suggest that the cultural variables explained between $35 \%$ and $65 \%$ variation in the eGovernment readiness indices when treated as the only explanatory variables in regression models. Observed jointly, cultural variables made a significant impact on eGovernment readiness. However, when observed individually, only two of the cultural variables are significant, i.e. Individualism and Power Distance Index. Uncertainty Avoidance Index is significant only in the regression model for Human Capital Index. The sign of each coefficient matches our expectation: IDV has a positive sign, while PDI has a negative impact on eGovernment readiness. Furthermore, standardized $\beta$ coefficients suggest that IDV is a relatively more important cultural construct in predicting eGovernment readiness than PDI. Interestingly MAS was not significant in any regression model, suggesting there are both masculine and feminine countries with a strong attitude toward implementing eGovernment initiative.

PDI coefficient has a negative sign in the regression model for TII. This result is consistent with the findings of Veiga, Floyd \& Dechants (2001). According to them, attitude toward ICT use will be enhanced by a decision and implementation process that increases users' sense of participation in the choice of new ICTs. We should therefore expect to find evidence of resistance in situations where new ICTs, and policy pertaining to their use, are implemented without the participation of members below top management.

UAI was used in many studies as a predictor of the likelihood of ICT adoption. Surprisingly, UAI appears to be significant in the case of HCI model only and with a positive sign suggesting that countries with a strong uncertainty avoidance would have higher adult literacy rate and gross enrolment ratio (components of $\mathrm{HCI}$ ).

IDV has a significant coefficient with the positive sign in the regression model for ePART. In an individualistic culture people seem to be more innovative in using new ICT to communicate with officials (government) and would expect that the officials would offer them new communication channels. Also individualistic cultures emphasize productivity. People in these cultures would use new ICTs to communicate with government and carry out their jobs. Finally, because the democratic societies are countries with a prevalent individualistic culture they incline to contact government to ask questions, find solutions for their problems and complete some obligations toward government (tax return, car registration, finding jobs, etc.)

In summary, based on regression models with cultural variables only, the first two hypotheses, i.e. $\mathrm{H} 1$ and $\mathrm{H} 2$ were confirmed.

For the reason explained in the data and methodology section GDP per capita was added to the list of explanatory variables in each regression model of eGovernment readiness. A summary of all regression models is presented in Table 5. However, before commenting on these results, there is a need for clarification of some methodological problems and justification for the estimation methods used.

To test normality and homoscedasticity assumptions two econometric tests have been applied to regression model residuals. The Jarque-Bera/Salmon-Kiefer tests test the null hypothesis that the regression model errors are normally distributed. The null hypothesis is rejected if the value of 
the test statistic is larger than the critical value. The test didn't confirm the normality assumption in the case of the TII, HCI and ePART regression models. The Breusch-Pagan test tests the homoskedasticity of residuals in a regression model. A regression model is homoskedastic if the model errors have a constant conditional variance, given the regressors (independent variables) and is said to be heteroskedastic if not. The null hypothesis is rejected if the value of the test statistic is larger than the critical value. The test did not confirm homoscedastic assumption in cases of the TII and HCI regression models residuals. To correct for possible heteroskedastic residuals White heteroskedastic corrections were applied (labeled as H.C. in Table 4). Only in the case of TII and eGOV regression models were slightly different results obtained. This time the IDV cultural variable was not significant, while previously it was significant in OLS regressions.

Since the three eGovernment readiness indices WMI, TII and HCI are components of an overall eGovernment readiness as well as ePART, it makes sense to treat them jointly, as we would expect that the residuals across these four regression models are correlated. Indeed, the correlation coefficients between the four series of residuals are all significant at the $1 \%$ level. Their absolute values are in the range 0.238 to 0.781 . In such a case the use of an alternative estimation method to OLS is recommended. The seemingly unrelated regression (SUR) model seems to be a plausible alternative even when all explanatory variables are the same as in our case. With the same set of explanatory variables (cultural variables plus GDP) SUR estimates are equal to OLS estimates, but the efficiency of the parameter estimates could be improved if explicit account were taken of the correlation between residuals across regression models. However, the obtained results from the SUR model did not change the significance of the cultural variables from OLS model.

Finally, checking that the insignificant coefficients for cultural variables are not in fact the results of multicollinearity, i.e. a high correlation between the independent variables (cultural variables and GDP per capita) was undertaken. One effect of collinearities between independent variables is that the standard error of ordinary least squares estimates tends to be inflated. This also means that we get a less efficient estimate of the regression coefficients. In this case reported $P$-values could be higher than the actual values, suggesting that the coefficients are insignificant when they are actually significant. From Pearson's correlation matrix presented in Table 3 it is evident that the absolute values of correlation coefficients between cultural variables and GDP are quite high ( 0.655 for PDI and 0.738 for IDV).

Table 5: Summary of regression results (models with cultural variables and GDP)

\begin{tabular}{|c|c|c|c|c|}
\hline Dependent variable & $\begin{array}{l}\text { Estimation } \\
\text { method }\end{array}$ & $\begin{array}{c}\text { Variable with significant } \\
\text { t-test at } 5 \% \text { level }\end{array}$ & $\boldsymbol{R}^{2}$ & $\begin{array}{l}\text { Part of } R^{2} \\
\text { attributed } \\
\text { to culture }\end{array}$ \\
\hline Web Measure Index & $\begin{array}{r}\text { OLS } \\
\text { OLS (H.C.) } \\
\text { SUR }\end{array}$ & $\begin{array}{l}\operatorname{GDP}(+) \\
\operatorname{GDP}(+) \\
\operatorname{GDP}(+)\end{array}$ & 0.45 & 0.014 \\
\hline $\begin{array}{l}\text { Telecommunication } \\
\text { Infrastructure Index }\end{array}$ & $\begin{array}{r}\text { OLS } \\
\text { OLS (H.C.) } \\
\text { SUR } \\
\end{array}$ & $\begin{array}{l}\text { PDI(-), IDV(+), MAS(-), GDP(+) } \\
\text { PDI(-), MAS(-), GDP(+) } \\
\text { PDI(-), IDV(+), MAS(-), GDP(+) }\end{array}$ & 0.86 & 0.016 \\
\hline Human Capital Index & $\begin{array}{r}\text { OLS } \\
\text { OLS (H.C.) } \\
\text { SUR }\end{array}$ & $\begin{array}{l}\mathrm{UAI}(+), \operatorname{GDP}(+) \\
\mathrm{UAI}(+), \operatorname{GDP}(+) \\
\mathrm{UAI}(+), \operatorname{GDP}(+)\end{array}$ & 0.43 & 0.042 \\
\hline $\begin{array}{l}\text { eGovernment } \\
\text { Readiness Index }\end{array}$ & $\begin{array}{r}\text { OLS } \\
\text { OLS (H.C.) } \\
\text { SUR }\end{array}$ & $\begin{array}{l}\operatorname{IDV}(-), \operatorname{GDP}(+) \\
\operatorname{GDP}(+) \\
-\end{array}$ & 0.74 & 0.012 \\
\hline eParticipation Index & $\begin{array}{r}\text { OLS } \\
\text { OLS (H.C.) } \\
\text { SUR }\end{array}$ & $\begin{array}{l}\operatorname{IDV}(+), \operatorname{GDP}(+) \\
\operatorname{IDV}(+), \operatorname{GDP}(+) \\
\operatorname{IDV}(+), \operatorname{GDP}(+)\end{array}$ & 0.45 & 0.044 \\
\hline
\end{tabular}

See Table 2 for description of variables 
The most frequently used remedy for coping with multicollinearity is to drop the variables suspected of causing multicollinearity, although it causes the problem of missing variables in the specified model. Since there is a high correlation between GDP, IDV and PDI, dropping any of these variables could be seen as a solution of the multicollinearity problem. However, the cultural indices are those variables whose impact we would like to measure and excluding them from the model could cause a specification problem - case of missing variable. Therefore an alternative approach has been used for the estimation of the eGovernment readiness model based on a robust technique of ridge regression designed for illconditioned problems. The key point of this procedure is to focus on the mean square error and trade the unbiased OLS estimator for a biased one with, possibly, a smaller mean square error. The ridge regressor is formed by adding an arbitrarily chosen scalar (biasing constant) to the normal equations of the OLS estimator. In applications, this constant is usually set to some small number and successively increased. The value of constant is chosen on the basis of criteria such as the stability of estimated coefficients as the value of a constant increases, reasonable signs, plausible magnitudes of the coefficients, and the reasonable sum of squared residuals. Ridge traces for each coefficient and $R^{2}$ versus biasing constant graphs were used to determine a value of the constant. Most of the coefficients in the eGOV regression model didn't change too much from their initial values, becoming stable for a value of the constant equal to 0.2 , while at the same time $R^{2}$ dropped from 0.769 to 0.752 . This result would suggest that the multicollinearity was not a serious problem in the regression model. SPSS for Windows version 11.5 provides a few collinearity diagnostic tools including tolerance, variance-inflation factor (VIF) and others. All these tools were used, but the results are not reported here. However, in all reported regression models VIF was well bellow 4 which is an arbitrary, but common cut-off criterion for deciding when a given independent variable displays "too much" multicollinearity.

In summary, multicollinearity does not seem to be a problem in eGovernment readiness regression models and the conclusion could be made that among cultural variables in regression models which include GDP only IDV, PDI and UAI seem to be significant in some models.

Based on regression model WMI was found not to be related to any cultural dimension, which means that all governments accepted that they have to implement ICTs as a tool to inform, interact, transact and network. Controlling a level of economic development (measured by GDP) in the regression model for WMI (general aptitude of government to employ eGovernment) it appears that general globalization trend in this area, i.e. wide acceptance of eGovernment initiative was not influenced by any cultural dimension.

Results of the regression model for TII are comparable with the results from Bagchi, Cerveny, Hart \& Peterson (2003) and confirm their findings. They have tested the impact of national culture on adoption of six information technologies. Since the TTI is a synthetic index composed from six primary indices similar to their six information technologies, it would be expected to get similar results for the synthetic indicator as they got for each individual indicator. In their case all cultural variables were significant with the same sign, though not the same cultural variables in each regression model for an individual IT. Also the coefficient of determination was in the same range as in their study.

The estimated HCI regression model shows that UAI is the only cultural dimension significant. For the overall eGovernment readiness, measured by eGOV and its regression model the result is inconclusive. The OLS model suggests that IDV is significant variable, but because of the problems with the heteroscedasticity, the OLS model with correction for heteroscedasticity is more reliable and in this model GDP is the only significant variable. Contributions of cultural dimensions to variation in eGovernment readiness regression models are from $1.4 \%$ to $4.4 \%$ (last column in Table 5). 
Returning back to four postulated hypotheses it could be said that the hypothesis H1 was moderately supported, i.e. the government of a country with the larger power distance do have a negative attitude toward increasing the level of eGovernment readiness. Hypothesis $\mathrm{H} 2$ was supported, i.e. the government of a country with a strong individualistic culture does have a positive attitude toward increasing the level of eGovernment readiness. However, hypothesis H3 was not supported, i.e. masculinity of the country has nothing to do with the attitude toward increasing the level of eGovernment readiness. Eventually, hypothesis $\mathrm{H} 4$ was only weakly supported, i.e. the government of a country with strong uncertainty avoidance culture does have a negative attitude toward increasing the level of eGovernment readiness.

\section{Concluding Remarks and Limitations}

This study is designed to examine whether differences in worldwide eGovernment readiness levels are explained by cultural variables. Our results give some support to this statement. Based on results from Table 3 - Table 5 it was found that national cultural indicators have a moderate impact on the eGovernment readiness worldwide. Among four cultural dimensions Individualism and Power Distance are the only significant variables that could be used to explain differences in level of eGovernment readiness.

This study has implications both for practice and for theory. It shows that cultural variables are relevant to the worldwide eGovernment readiness. Indeed, the empirical analysis found that the model with both economic and cultural variables explains between $42 \%$ and $85 \%$ of the variability in eGovernment readiness indices (cultural variables alone contributed from $1.4 \%$ to $4.4 \%$ ). Among cultural variables in regression models which include GDP only IDV, PDI and UAI seem to be significant in some models. From regression model for WMI it follows that general aptitude of government to employ eGovernment via governmental websites was not influenced by any cultural dimension. Results of the regression model for TII confirm that cultural variables such as PDI, IDV and MAS were significant. Finally, the estimated HCI regression model shows that $\mathrm{UAI}$ is the only cultural dimension significant.

In addition to this empirical finding the study also has implication for diffusion theory, or adoption of a new technology theory. Empirical results justify the inclusion of cultural variables and demonstrate the need to broaden the adoption of a new technology theory in the area of the influence of social norms.

Bridges.org (2001) suggests: “... the unique cultural and historical environment of a region must be taken into account as part of a national ICT policy to truly gauge the country's e-readiness for the future."

This study is subject to certain reservations. National culture constructs were derived from the Hofstede cultural model. Since there are other cultural models it would be necessary to check whether cultural constructs based on an alternative theory of culture to Hofstede's theory confirm the impact that national culture has on the eGovernment readiness. Additionally, religion as an important cultural factor could be considered for inclusion in regression model as a control variable or as an alternative cultural proxy variable. Also, alternative definitions and indicators of eGovernment readiness should be used to see how robust the results in this study are, where the eGovernment readiness is based on the United Nations definition. Finally, other factors such as culture of government and ruling system should be considered in the regression model as they might have impact on the eGovernment readiness.

\section{References}

Altman, D. (2002). Prospects for e-government in Latin America: Satisfaction with democracy, social accountability, and direct democracy. International Review of Public Administration, 7(2), 5-20. 
Bagchi, K., Cerveny, R., Hart, P., \& Peterson, M. (2003). The influence of national culture in information technology product adoption. In Proceedings of the Ninth Americas Conference on Information Systems, 957-965.

Bierens, H. J. (2004). EasyReg International. Department of Economics, Pennsylvania State University, University Park, PA.

Bretschneider, S., Gant, J., \& Ahn, M. (2003). A general model of e-government service adoption: Empirical exploration. Public Management Research Conference, Georgetown Public Policy Institute Washington, D.C., October 9-11, 2003. Retrieved May 10, 2004, from http://www.pmranet.org/conferences/georgetownpapers/Bretschneider.pdf

Bridges.org (2001). Comparison of e-Readiness assessment models. Retrieved April 1, 2004 from http://www.bridges.org/ereadiness/report.html

Bui, T. X., Sankaran, S., \& Sebastian, I. M. (2003). A framework for measuring national e-readiness. International Journal of Electronic Business, 1(1), 3-22.

Chanchani, S., \& Theivanathampillai, P. (2002). Typologies of culture. University of Otago, Department of Accountancy and Business Law Working Papers Series, 04_10/02. Dunedin: University of Otago.

Choucri, N., Maugis, V., Madnick, S. \& Siegel, M. (2003). Global e-Readiness - for what? MIT Sloan School of Management Research Paper 177.

CIA (2003). The World Fact book. Retrieved April 1, 2004, from http://www.cia.gov/cia/publications/factbook

Graafland-Essers, I., \& Ettedgui, E. (2003). Benchmarking e-government in Europe and the US. RAND, $M R-1733-E C, 2003$. Retrieved May 10, 2004, from http://www.rand.org/publications/MR/MR1733/MR1733.pdf

Hargittai, E. (1999). Weaving the Western web: Explaining differences in Internet connectivity among OECD countries. Telecommunications Policy, 23(10/11).

Hofstede, G. (1980). Culture's consequences: International differences in work-related values. Beverly Hills, California: Sage Publications.

Hofstede, G. (1981). Culture and organizations. International Studies of Management and Organization, 10(4), 15-41.

Hofstede, G. (1983). National cultures in four dimensions - A research-based theory of cultural differences among nations. International Studies of Management and Organization, 13(1-2), 46-74.

Hofstede, G. (2004). Geert Hofstede cultural dimensions. Retrieved November 19, 2004, from http://www.geert-hofstede.com/hofstede dimensions.php

Holden, S. H., Norris, D. F., \& Fletcher, P. D. (2003). Electronic government at the grass roots: Contemporary evidence and future trends. Proceedings of the 36th Hawaii International Conference on System Sciences. Big Island, Hawaii, January 06 - 09, 2003. Retrieved May 10, 2004, from http://csdl.computer.org/comp/proceedings/hicss/2003/1874/05/187450134c.pdf

Johns, S. K., Smith, M., \& Strand, C. A. (2003). How culture affects the use of information technology. Accounting Forum, 27(1), 84-109.

Kim, K-J., \& Bonk, C. J. (2002). Cross-cultural comparisons of online collaboration. Journal of ComputerMediated Communication, 8(1). Retrieved April 1, 2004, from http://www.ascusc.org/jemc/vol8/issue1/kimandbonk.html

Kovačić, Z. (2005). A brave new eWorld? An exploratory analysis of worldwide eGovernment readiness, level of democracy, corruption and globalization. International Journal of Electronic Government Research, 1(3), 15-32.

Maitland, C.F., \& Bauer, J.M. (2001). National level culture and global diffusion: The case of the Internet. In C. Ess (Ed.), Culture, technology, communication: Towards an intercultural global village (pp. 87128). Albany, NY: State University of New York Press.

McSweeney, B. (2002). Hofstede's model of national cultural differences and their consequences: A triumph of faith - a failure of analysis. Human Relations, 55(1), 89-118. 
Robinson, K.K., \& Crenshaw, E.M. (1999). Cyber-space and post-industrial transformations: A crossnational analysis of Internet development. Retrieved May 10, 2004, from http://www.soc.sbs.ohiostate.edu/emc/RobisonCrenshawCyberla.pdf

Slack, J. D., \& Wise, J. M. (2002). Cultural studies and technology. In Livingstone, S., \& Lievrouw, L. (Eds.), Handbook of new media (pp. 221-235). London: Sage.

Sørnes, J-O., Stephens, K. K., Sætre, A. S., \& Browning, L. D. (2004). The reflexivity between ICTs and business culture: Applying Hofstede's theory to compare Norway and the United States. Informing Science Journal, 7, 1-30. Retrieved May 10, 2004, from http://inform.nu/Articles/Vol7/v7p001-030211.pdf

Turban, E., King, D., Lee, J., Warkentin, M., \& Chung, H. M. (2002). Electronic commerce 2002: A managerial perspective. Upper Saddle River: Prentice Hall.

United Nations, Division for Public Economics and Public Administration and American Society for Public Administration (2001). Benchmarking e-government: A global perspective --- Assessing the progress of the UN member states. Retrieved May 10, 2004, from http://www.unpan.org/egovernment/Benchmarking\%20E-gov\%202001.pdf

United Nations, Division for Public Economics and Public Administration and American Society for Public Administration (2003). UN global e-government survey. Retrieved May 10, 2004, from http://unpan1.un.org/intradoc/groups/public/documents/un/unpan016066.pdf

Veiga, J. F., Floyd, S., \& Dechant, K. (2001). Towards modeling the effects of national culture on IT implementation and acceptance. Journal of Information Technology, 16(3), 145-158.

West, D. M. (2000). Assessing e-government: The Internet, democracy and service delivery by state and federal governments. Washington, D.C.: World Bank. September 2000. Retrieved May 10, 2004, from http://www.Worldbank.org/publicsector/egov/EgovReportUS00.htm

West, D.M. (2001). World markets research centre global e-government survey 2001. Retrieved May 10, 2004, from http://www.worldmarketsanalysis.com/pdf/e-govreport.pdf Available also at http://www.brown.edu/Departments/Taubman_Center/polreports/egovt01int.html

\section{Acknowledgements}

I would like to thank John Green, Senior Lecturer in the School of Information and Social Sciences at the Open Polytechnic of New Zealand for valuable comments on the first draft of this paper. I also take this opportunity to thank those anonymous Conference reviewers for their time and extremely valuable work which helped me to improve the final version of this paper. However, the author should be held responsible for any remaining errors.

\section{Biography}

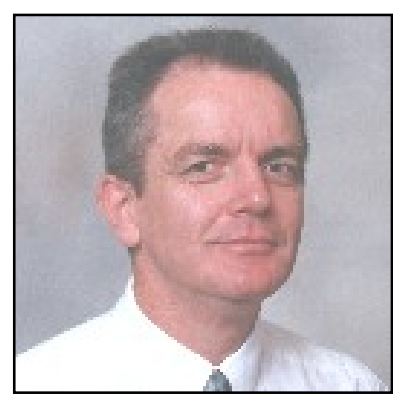

Dr Zlatko J Kovačić is a Senior Lecturer in the School of Information and Social Sciences at the Open Polytechnic of New Zealand. Zlatko has a varied academic background and research interests, ranging from core interests relating to IT careers, learning and teaching, to eCommerce, eLearning, time series analysis, multivariate analysis and Web (data) mining. His current research is focused on social and cultural aspects of eGovernment and on cognitive processes in distance education using computers and communications technologies. 